\title{
Incorporation of Temperature and Solar Radiation Thresholds to Modify a Lettuce Downy Mildew Warning System
}

\author{
B. M. Wu, A. H. C. van Bruggen, K. V. Subbarao, and H. Scherm
}

First and third authors: Department of Plant Pathology, University of California, Davis, c/o U.S. Agricultural Research Station, 1636 E. Alisal St., Salinas 93905; second author: Biological Farming Systems, Wageningen University and Research Centre, the Netherlands; and fourth author: Department of Plant Pathology, University of Georgia, Athens 30602.

Accepted for publication 19 February 2002.

\begin{abstract}
Wu, B. M., van Bruggen, A. H. C., Subbarao, K. V., and Scherm, H. 2002. Incorporation of temperature and solar radiation thresholds to modify a lettuce downy mildew warning system. Phytopathology 92:631636.

The effect of temperature on infection of lettuce by Bremia lactucae was investigated in controlled environment studies and in the field. In controlled conditions, lettuce seedlings inoculated with B. lactucae were incubated at $15,20,25$, or $30^{\circ} \mathrm{C}$ during a 4 -h wet period immediately after inoculation or at the same temperatures during an 8-h dry period after the 4-h postinoculation wet period at $15^{\circ} \mathrm{C}$. High temperatures during wet and dry periods reduced subsequent disease incidence. Historical data from field studies in 1991 and 1992, in which days with or without infection had been identified, were analyzed by comparing average air temperatures during 0600 to 1000 and 1000 to 1400 Pacific standard time (PST) between the two groups of days. Days without infection had significantly higher temperatures (mean $21.4^{\circ} \mathrm{C}$ ) than days with infection $\left(20.3^{\circ} \mathrm{C}\right)$ during 1000 to 1400 PST $(P<0.01)$ but not during 0600 to 1000 PST. Therefore, temperature thresholds of 20 and

disease warning system that predicts infection when morning leaf wetness lasts $\geq 4 \mathrm{~h}$ from 0600 PST. No infection was assumed to occur if average temperature during these periods exceeded the thresholds. Based on nonlinear regression and receiver operating characteristic curve analysis, the leaf wetness threshold of the previous warning system was also modified to $\geq 3$-h leaf wetness ( $\geq 0900$ PST). Furthermore, by comparing solar radiation on days with infection and without infection, we determined that high solar radiation during 0500 to 0600 PST in conjunction with leaf wetness ending between 0900 and 1000 PST was associated with downy mildew infection. Therefore, instead of starting at 0600 PST, the calculation of the 3-h morning leaf wetness period was modified to start after sunrise, defined as the hour when measured solar radiation exceeded $8 \mathrm{~W} \mathrm{~m}^{-2}$ (or $41 \mu \mathrm{mol} \mathrm{m} \mathrm{m}^{-2} \mathrm{~s}^{-1}$ for photon flux density). The modified warning system was compared with the previously developed system using historical weather and downy mildew data collected in coastal California. The modified system was more conservative when disease potential was high and recommended fewer fungicide applications when conditions were not conducive to downy mildew development.
\end{abstract} $22^{\circ} \mathrm{C}$ for the 3-h wet period after sunrise and the subsequent 4-h postpenetration period, respectively, were added to a previously developed
Additional keywords: disease forecasting, Lactuca sativa.
The response of Bremia lactucae Regel, the causal agent of downy mildew of lettuce (Lactuca sativa L.), to environmental conditions has been studied extensively in an effort to develop guidelines for improved timing of fungicide applications. Asexual sporulation of the pathogen is restricted to periods of darkness, high humidity, and low wind speed $(5,15,16)$. Spore release is triggered by light and enhanced by a decrease in humidity $(2,13$, 17). Following spore release, at least $3 \mathrm{~h}$ of leaf wetness and suitable temperatures (optimum $15^{\circ} \mathrm{C}$ ) are required for spore germination and host penetration $(6,9,18)$. If conditions favorable for infection do not occur immediately following spore release, spores rarely survive during dry and sunny days because of the negative effects of solar radiation (especially in the UVB spectrum) and high temperatures $(20,21)$. Along the central coast of California, high humidity caused by advection of moist air from the ocean at night provides conditions generally favorable for sporulation by the pathogen $(12,22)$. Cool mornings with prolonged leaf wetness occur frequently, providing conditions suitable for infection and resulting in destructive epidemics of downy mildew in commercial lettuce fields.

Corresponding author: B. M. Wu: E-mail address: bmwu@ucdavis.edu

Publication no. P-2002-0329-01R

This article is in the public domain and not copyrightable. It may be freely reprinted with customary crediting of the source. The American Phytopathological Society, 2002.
Because insensitivity to currently registered eradicant fungicides is prevalent in populations of B. lactucae in coastal California $(4,14)$, lettuce producers commonly rely on regular applications of protectant fungicides to control downy mildew. Most of these applications are unnecessary when weather is unfavorable for disease development (8), although severe disease can occasionally result from poor timing of sprays when conditions are highly conducive.

To reduce fungicide applications and improve control of downy mildew of lettuce, a disease warning system was developed by Scherm et al. (8) and Scherm and van Bruggen (9-13) who demonstrated that leaf wetness duration (LWD) in the morning is the most important variable that determines the intensity of the disease in coastal California (12). In this system, it was assumed that spores are released early in the morning and infection could occur during the same morning if leaf wetness extended until at least 1000 Pacific standard time (PST) $(8,13)$. Thus, fungicide advisories were issued when leaf wetness persisted until 1000 PST or longer and no fungicide had been applied during the previous 7 days (8). Field studies demonstrated that compared with a calendar-based schedule of three sprays, 67 to $100 \%$ of the sprays could be reduced when applications were made according to the warning system (8).

The morning LWD-based downy mildew warning system was subsequently modified by incorporating modules for sporulation (16) and spore survival $(20,21)$. When this system was evaluated between 1996 and 1998, however, it recommended too many 
spray applications in some seasons when downy mildew either did not develop or the incidence was very low (22). Initial analyses of weather and downy mildew data suggested that disease development may have been checked by extremely high temperatures, yet the system failed to skip unnecessary sprays (22). In other seasons, infection events predicted by the warning system were insufficient to explain all increases in downy mildew intensity (22). At least one major infection period presumably missed by the modified system in each of two field studies suggested that LWD ending between 0900 and 1000 PST likely provided opportunity for infection. This is likely because spore germination and infection were assumed to have begun at 0600 PST in the original system (8), although spore release may start earlier depending on the season and location. Because spore release of $B$. lactucae is triggered by light (17), morning LWD from sunrise is likely to be epidemiologically more important than LWD starting at a fixed time.

The objectives of this study were to investigate the effects of temperature on infection of lettuce by B. lactucae, to refine the morning LWD threshold used in prediction of downy mildew of lettuce, to incorporate the results into a previously developed disease warning system, and to test the new system with historical weather and disease data.

\section{MATERIALS AND METHODS}

Controlled environment experiments. The effect of temperature on infection by B. lactucae was studied in two series of growth chamber experiments. Lettuce seedlings of cv. Alpha at the three-leaf stage were spray-inoculated with a spore suspension of B. lactucae (pathotype V) as described previously (21), and inoculated seedlings were placed in moist chambers for $4 \mathrm{~h}$. In the first experiment, inoculated seedlings were incubated at $15,20,25$, or $30^{\circ} \mathrm{C}$ during the 4-h wet period, after which leaves were dried in an airflow for $10 \mathrm{~min}$ and seedlings were incubated at $15^{\circ} \mathrm{C}$ for 6 days at ambient humidity (50 to 75\%) in a growth chamber with a 12:12-h light/dark cycle. In the second experiment, inoculated seedlings were incubated at $15^{\circ} \mathrm{C}$ during the 4-h wet period and exposed to $15,20,25$, or $30^{\circ} \mathrm{C}$ for $8 \mathrm{~h}$ after drying of the leaves. Subsequently, seedlings were also incubated at $15^{\circ} \mathrm{C}$ for 6 days at ambient humidity in the growth chamber. In both series of experiments, the seedlings were misted with water and placed in moist chambers in the evening of the seventh day after inoculation to allow subsequent sporulation by $B$. lactucae. Seedlings were evaluated for infection (as evidenced by the presence of sporulation) on the ninth day after inoculation, and the percentage of in- fected plants was recorded for each treatment. The two experiments were completed three and five times, respectively, with at least 100 seedlings inoculated per treatment. The relationship between disease incidence and temperature was analyzed using regression analysis (SAS release 7.0, SAS Institute Inc., Cary, NC).

Field data analysis. The analysis utilized hourly weather data (including LWD, temperature, relative humidity, and solar radiation) and downy mildew observations from 13 commercial lettuce fields along the central coast of California in 1991 and 1992 (12). In each field, an area of $8.1 \times 50 \mathrm{~m}^{2}$, in which no fungicides effective against oomycetes were applied, was used to evaluate at least 70 lettuce plants for disease incidence at 1- to 10-day intervals. Infection was assumed to have occurred within a 3-day period 7 to 9 days before the observation of new downy mildew lesions $(11,12)$. The data set encompassed a total of 181 site-days, of which 61 were classified as infection days (12).

Temperature effects. In a previous analysis (12), each day in the field data set was divided into three periods, morning (0600 to 1400 PST), afternoon (1400 to 2200 PST), and night (2200 to 0600 PST the following day), and no significant differences were found in average air temperature during the morning between infection days and days without infection (12). In the present study, each morning period was further divided into two intervals, 0600 to 1000 and 1000 to 1400 PST. Average temperatures during these two periods were calculated for each day, and KolmogorovSmirnov tests were used to compare temperatures between infection days and days without infection.

Morning LWD threshold. In a separate analysis, all days in the field data set were placed in one of seven groups based on the hour when leaf wetness ended $(<0600,0600,0700,0800,0900$, 1000 , and $>1000 \mathrm{~h}$ PST). The number of infection days and average ending times of leaf wetness were then calculated for each group. A logistic model was subsequently fitted to the relation between percentage of infection days and the ending time of leaf wetness using nonlinear regression (SAS Institute). To determine the most appropriate leaf wetness threshold, a receiver operating characteristic (ROC) curve was derived for thresholds of 0700 to 1100 PST by plotting the frequency of true positives against the frequency of false positives (23).

Radiation threshold. All days in the field data set were placed in one of three groups, depending on whether leaf wetness ended before 0900 PST, between 0900 and 1000 PST, or after 1000 PST. Within each group, average photon flux density during 0500 to 0600, 0600 to 0700 , and 0600 to 1000 PST was compared between infection days and days without infection using the Kolmogorov-Smirnov tests. This analysis was done to determine
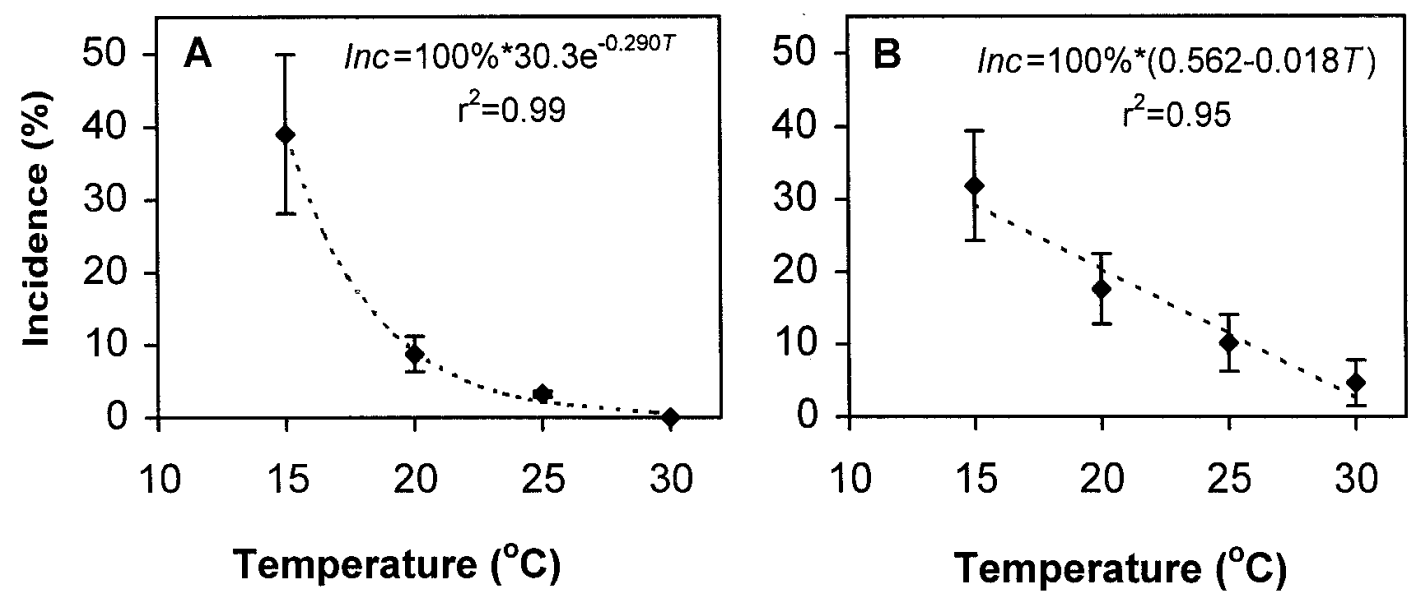

Fig. 1. Effect of temperature during $\mathbf{A}$, the penetration and $\mathbf{B}$, postpenetration periods on subsequent incidence of downy mildew of lettuce, caused by Bremia lactucae. Seedlings were inoculated and exposed to a 4-h wet period (incubated at the temperatures shown in $\mathbf{A}$ and at $15^{\circ} \mathrm{C}$ in $\mathbf{B}$ ) followed by an 8-h dry period (incubated at $15^{\circ} \mathbf{C}$ in $\mathbf{A}$ and at the temperatures shown in $\mathbf{B}$ ). Data points are means and standard errors of three or five experiments, with at least 100 seedlings inoculated per experiment. Dashed lines represent $\mathbf{A}$, exponential and $\mathbf{B}$, linear regression models fitted to the data. 
whether the time of sunrise, which could have affected the time of spore release of $B$. lactucae, interacted with morning LWD in affecting infection.

Modification of downy mildew warning system. The original warning system (8) was based solely on an LWD-based infection module. The system predicted infection whenever morning leaf wetness extended until at least 1000 PST. Based on results from the above analyses, the original warning system was modified and expanded. The LWD threshold was shortened to $3 \mathrm{~h}$, whereby leaf wetness started to accrue when measured photon flux density increased above $41 \mu \mathrm{mol} \mathrm{m} \mathrm{m}^{-2} \mathrm{~s}^{-1}$ rather than starting at a fixed time of $0600 \mathrm{PST}$ as in the original system. A solar radiation threshold of $8 \mathrm{~W} \mathrm{~m}^{-2}$ was used in fields where solar radiation was measured instead of photon flux density. Negative effects of high temperature on infection also were included, whereby no infection was assumed to occur if average air temperature exceeded $20^{\circ} \mathrm{C}$ during the 3-h wet period or $22^{\circ} \mathrm{C}$ during the subsequent 4-h (wet or dry) period.

Comparison of the two warning systems with historical data. Hourly weather data collected in the 1991 and 1992 field studies described previously were used as input for the original and modified warning systems. Infection days deduced from symptom observations were compared with infection days predicted by the two systems. Frequencies of false negatives and false positives were calculated and compared.

In an additional comparison, weather and disease data from 14 field studies along the central coast of California between 1993 and 1998 were used to test both systems $(8,22)$. Hourly weather variables, including air temperature, LWD, and solar radiation or photon flux density (not measured in three of the trials), recorded in or in the vicinity (within $50 \mathrm{~m}$ ) of lettuce fields, served as inputs for both systems. Disease incidence was assessed every 2 to 14 days for studies in 1995 to 1998, whereas only final disease incidence was recorded in 1993 and 1994. During each assessment, 50 or 100 plants were evaluated by diagonal passes. Disease progression in untreated plots was then compared with infection days predicted by the two warning systems. The 14 field studies were further classified into groups with high or low downy mildew potential, depending on whether final disease incidence was above or below $50 \%$. The number of fungicide applications recommended by the two warning systems was calculated for the two groups.

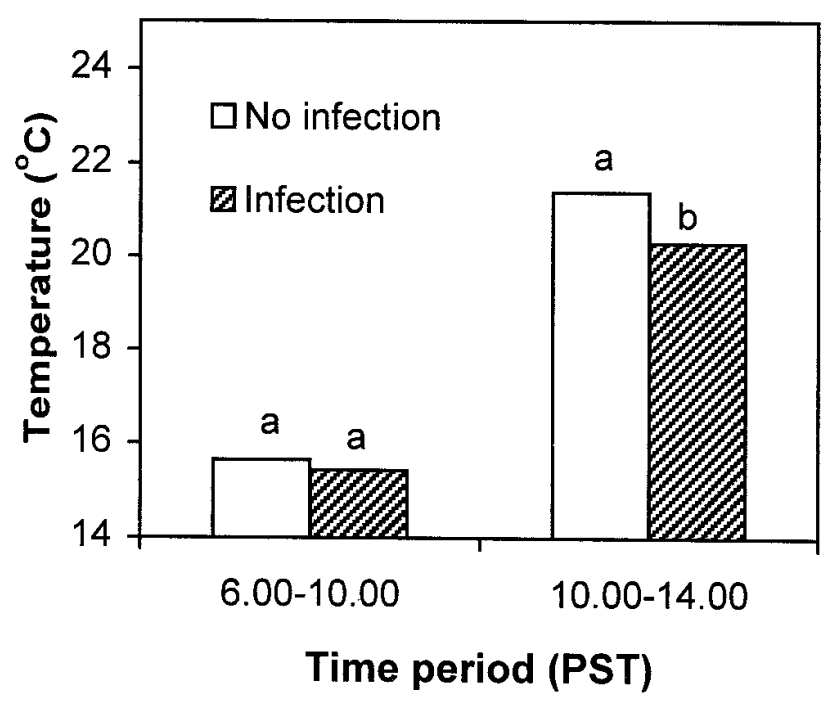

Fig. 2. Average air temperatures during different periods on days with infection $(n=61)$ and without infection $(n=120)$ by Bremia lactucae based on observations in lettuce fields in coastal California in 1991 and 1992 (12). Different letters indicate significant differences in the Kolmogorov-Smirnov tests. PST $=$ Pacific standard time.

\section{RESULTS}

Controlled environment studies. When lettuce seedlings were exposed to a range of temperatures during the 4-h wet period immediately after inoculation, subsequent downy mildew incidence decreased exponentially as temperature increased from 15 to $30^{\circ} \mathrm{C}$, with no plants infected at $30^{\circ} \mathrm{C}$ (Fig. $1 \mathrm{~A} ; r^{2}=0.99, P<$ 0.01 ). When temperature increased from 15 to $30^{\circ} \mathrm{C}$ during the 8 -h dry period following the initial 4-h wet period in the second experiment, disease incidence decreased linearly (Fig. $1 \mathrm{~B} ; r^{2}=0.95$, $P<0.01)$. Based on results in Figure 1A and those reported previously (18), an upper limit of $20^{\circ} \mathrm{C}$ for spore germination and penetration was used in the modified warning system described below.

Temperature threshold. In the 1991 and 1992 field data sets, average temperatures on infection days and days without infection did not differ significantly during 0600 to 1000 PST (Fig. 2). During 1000 to 1400 PST, however, temperature averaged $20.3^{\circ} \mathrm{C}$ on days with infection, significantly lower $(P=0.002)$ than on days without infection $\left(21.4^{\circ} \mathrm{C}\right)$. Based on results in Figure 2 and those from the controlled environment studies (Fig. 1B), an upper limit of $22^{\circ} \mathrm{C}$ for postpenetration development of B. lactucae was used in the modified warning system.
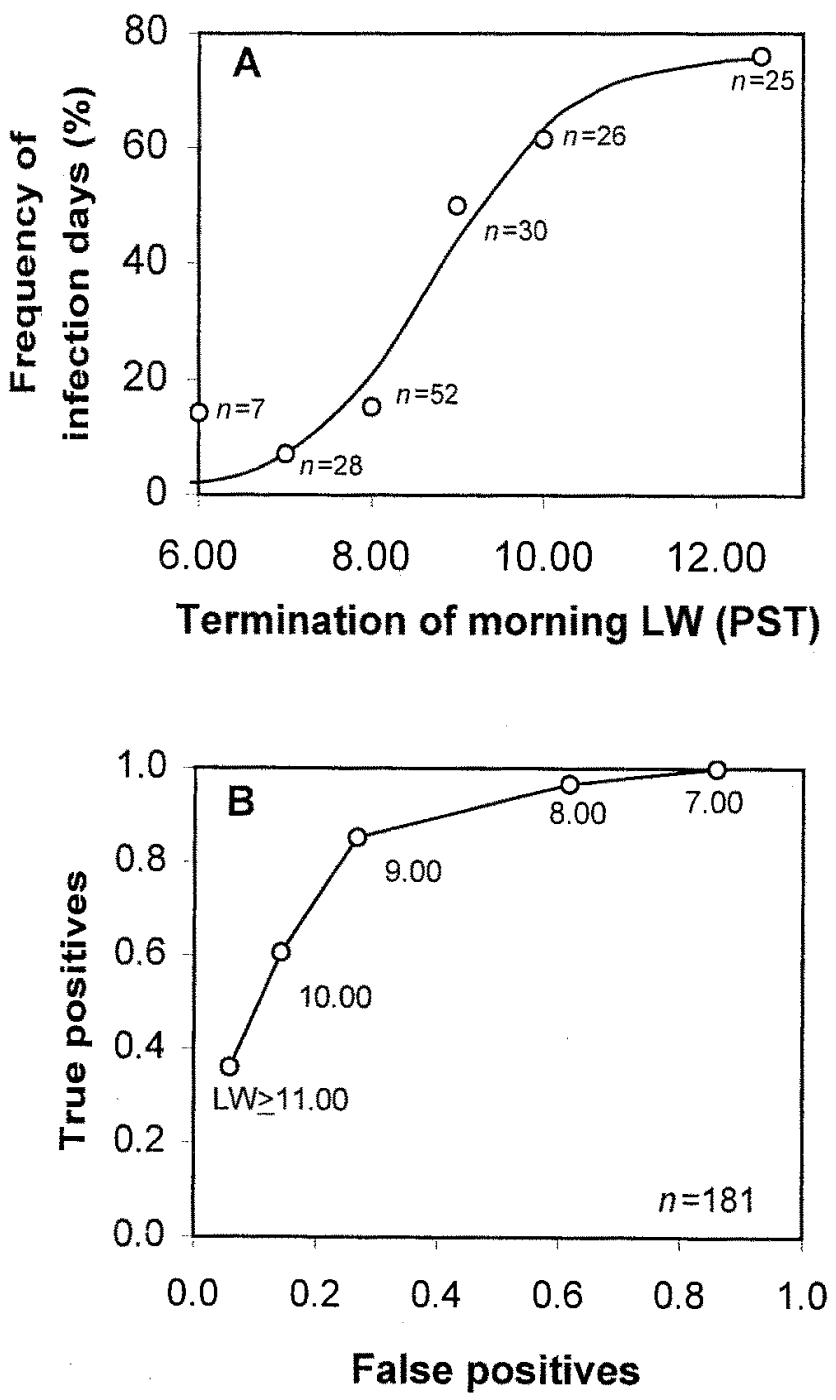

Fig. 3. A, Frequency of infection days by Bremia lactucae with leaf wetness (LW) ending at different times in the morning, based on observations in lettuce fields in coastal California in 1991 and 1992 (12), and B, receiver operating characteristic curve describing true positive and false positive predictions of infection days using different thresholds for ending time of leaf wetness $(\mathrm{LW})$. PST $=$ Pacific standard time. 
Morning LWD threshold. From the historical data, 13, 7, 28, $52,30,26$, and 25 days were classified into groups in which morning LWD ended at <0600, 0600 (dried between 0600 and $0700 \mathrm{~h}$ ), 0700, 0800, 0900, 1000, and $\geq 1100$ PST, respectively. A logistic model described the relationship between frequency of infection days and end of morning leaf wetness (Fig. 3A). Nearly $50 \%$ of days with leaf wetness ending between 0900 and 1000 PST were infection days, while very few of the days with leaf wetness ending before 0900 PST were infection days. For a downy mildew warning system based solely on ending time of morning leaf wetness, the frequency of false positives decreased from 0.86 to 0.06 as the cutoff for leaf wetness increased from 0700 to 1100 PST, but the frequency of true positives also decreased from 1.00 to 0.36 (Fig. 3B). Based on the shape of the ROC curve, the most appropriate ending time of leaf wetness was 0900 PST.

Radiation threshold. When leaf wetness ended before 0900 PST or after 1000 PST, no significant difference $(P=0.40$ and 0.25 , respectively) in photon flux density was observed between days with infection and days without infection (Fig. 4). However, when leaf wetness ended between 0900 and 1000 PST, average photon flux density from 0500 to 0600 PST was significantly $(P=$ $0.0006)$ higher on infection days than on days without infection (Fig. 4). This suggests that days with leaf wetness ending between 0900 and 1000 PST were more likely to have been infection days when the sunlight increased early. Thus, a photon flux density threshold of $41 \mu \mathrm{mol} \mathrm{m} \mathrm{m}^{-2} \mathrm{~s}^{-1}$ (or an approximately equivalent solar radiation threshold of $8 \mathrm{~W} \mathrm{~m}^{-2}$ ) was used in the modified warning system to initiate counting of leaf wetness hours (Fig. 4).

Comparison of the two warning systems with historical data. When predictions of infection days by the two warning systems were compared with infection days observed during the 1991 and 1992 field studies, the modified system was more accurate than the original system, with lower frequencies of false positives and false negatives (Fig. 5). In subsequent field studies during 1993 to 1998 , the modified system generally predicted fewer infection days when weather was not conducive to downy mildew development. For example, in an experiment in 1997 (Fig. 6A), the original system recommended one unnecessary spray although no disease progress was observed in untreated plots. The modified system predicted no infection in this experiment. In cases when

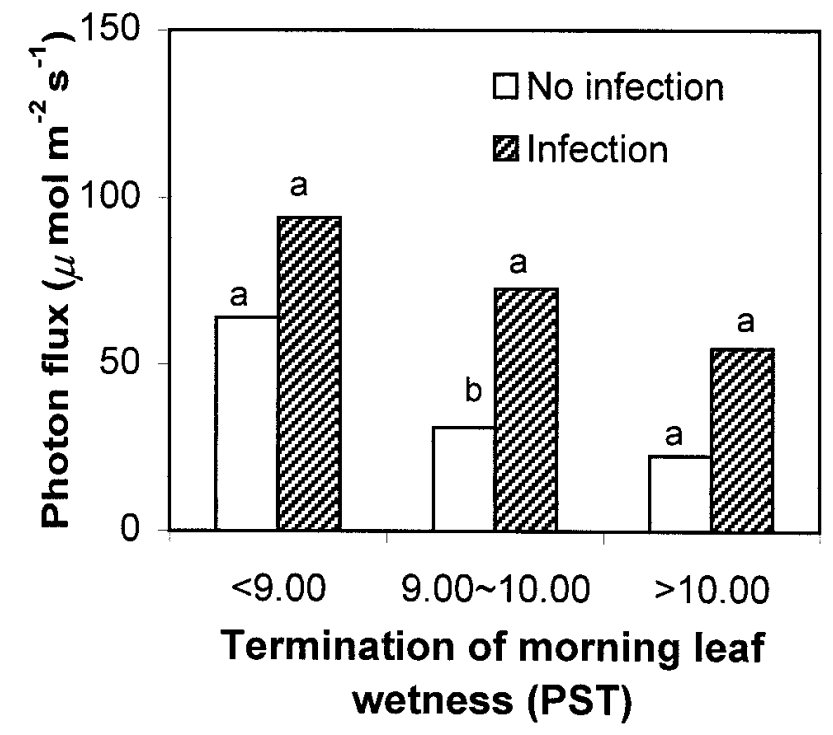

Fig. 4. Photon flux density from 0500 to 0600 Pacific standard time (PST) on infection days and days without infection by Bremia lactucae with morning leaf wetness ending at different times based on observations in lettuce fields in central California in 1991 and 1992 (12). Means are based on data from 11 to 89 days. Different letters indicate significant differences in the Kolmogorov-Smirnov test. disease potential was moderate, the modified system predicted either more or fewer infection days, depending on the experiment, but the timing of the first recommended spray was generally earlier. In one experiment (Fig. 6B), two infection periods predicted by the modified system corresponded to two subsequent major increases in downy mildew incidence in untreated plots, but the original system missed the second infection period. When disease potential was very high, such as in the experiments shown in Figure $6 \mathrm{C}$ and $\mathrm{D}$, the modified system almost always predicted more infection days and sometimes recommended more sprays.

When the 14 field studies were placed in two groups based on downy mildew incidence above or below $50 \%$, the modified system recommended the same number or fewer sprays in experiments with low disease potential but recommended the same number or more sprays when disease potential was high (Table 1). When disease potential was high, the average number of sprays recommended by the modified system (2.75) was greater than that recommended by the original system (2.00) and approached the number of sprays used in a typical calendar-based schedule (three sprays). Moreover, the modified system often recommended the first spray earlier than the original system even if the total number of sprays was equal. Thus, the modified system was more conservative than the original system under the conditions tested.

\section{DISCUSSION}

Downy mildew of lettuce has long been known to be less severe during hotter seasons and in areas with high temperatures $(1,15)$. High temperature was previously shown to reduce germination and penetration by B. lactucae (9). In coastal California, however, temperatures during extended morning leaf wetness periods are generally conducive to germination and penetration by $B$. lactucae (12) even during hot summers; thus, high temperature is unlikely to limit these two processes in this geographical area. The research reported here now provides evidence that high temperature during postpenetration establishment can affect development of the disease. As demonstrated in this study, downy mildew incidence decreased following exposure to high temperatures after the initial 4-h wet period in the controlled environment studies and there was a significant difference in air temperatures between in-

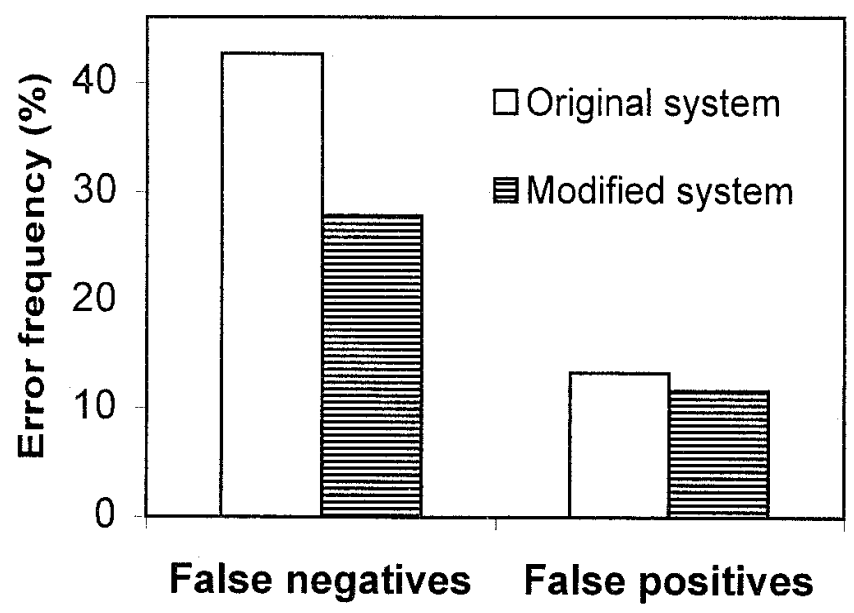

Fig. 5. Frequency of false negative and false positive predictions of infection days by the original and modified downy mildew warning systems, based on observations in lettuce fields in central California in 1991 and 1992 (12). The original system issued spray advisories when measured leaf wetness, beginning at 0600 Pacific standard time, exceeded a duration of $4 \mathrm{~h}$ and no fungicide had been applied for 7 days. The leaf wetness threshold in the modified system was altered to $\geq 3$-h leaf wetness after sunrise, and spray advisories were issued only when average temperature was $<20^{\circ} \mathrm{C}$ during the 3 -h wet period and $<22^{\circ} \mathrm{C}$ during the subsequent 4 -h period. 
fection days and days without infection during 1000 to 1400 PST (the time that would most likely correspond to postpenetration establishment) in the field.

Sargent et al. (7) determined that germ tubes and appressoria of B. lactucae form within 2- to 3-h postinoculation and that penetration of host epidermal cells is completed within 3 to $4 \mathrm{~h}$ after inoculation. Following penetration, a primary vesicle is formed within the epidermal cell, which subsequently forms a secondary vesicle. The secondary vesicle develops slowly over the next $9 \mathrm{~h}$. Nuclear division does not occur until after the cytoplasm moves into the secondary vesicle around $13 \mathrm{~h}$ after inoculation, when active parasitism by $B$. lactucae commences. There is thus an 8- to 9-h interval between penetration and establishment of active parasitism. Studies on Phytophthora infestans and B. lactucae showed that once active parasitism is established, these pathogens can survive relatively high temperatures $(11,19)$. For downy mildew of lima bean, however, high temperature after infection was found to check disease development (3). These conflicting results may be due to the different times (before or after establishment of active parasitism) when high-temperature treatments were applied.

Although temperature is an important determinant of infection by $B$. lactucae, LWD in the morning remains the most critical factor. However, different from the original downy mildew warning system (8), which used a morning leaf wetness threshold of 1000 PST to determine when to issue spray advisories, we occasionally observed infection on days when leaf wetness ended between 0900 and 1000 PST. Spore release by B. lactucae is triggered at sunrise (17) around 0600 PST (the time at which the original warning system began to accrue LWD) during the summer in coastal California. Thus, sporangia released and deposited around sunrise in the summer will have at least $3 \mathrm{~h}$ of leaf wetness if morning LWD extends until 0900 PST. Using a fixed threshold of morning leaf wetness lasting from 0600 to 1000 PST, the original warning system likely missed some infection days (false negatives). Based on a re-analysis of historical data, a solar radiation threshold was empirically deduced as a starting point for measuring morning LWD. This threshold needs to be tested further under laboratory and field conditions, but a limited testing based on historical data is offered in this study. By using a shortened 3-h leaf wetness threshold starting at sunrise and incorporating temperature limitations on germination penetration and postpenetration establishment of B. lactucae, the modified system predicted fewer infection days and recommended omitting one to three unnecessary sprays when weather was not conducive to downy mildew development. The modified system also recommended the first spray earlier and more sprays than the original system under conditions of high disease potential. The comparison between the modified and original system was done on historical data primarily because the importance of a solar radiation threshold in conjunction with the new morning LWD threshold
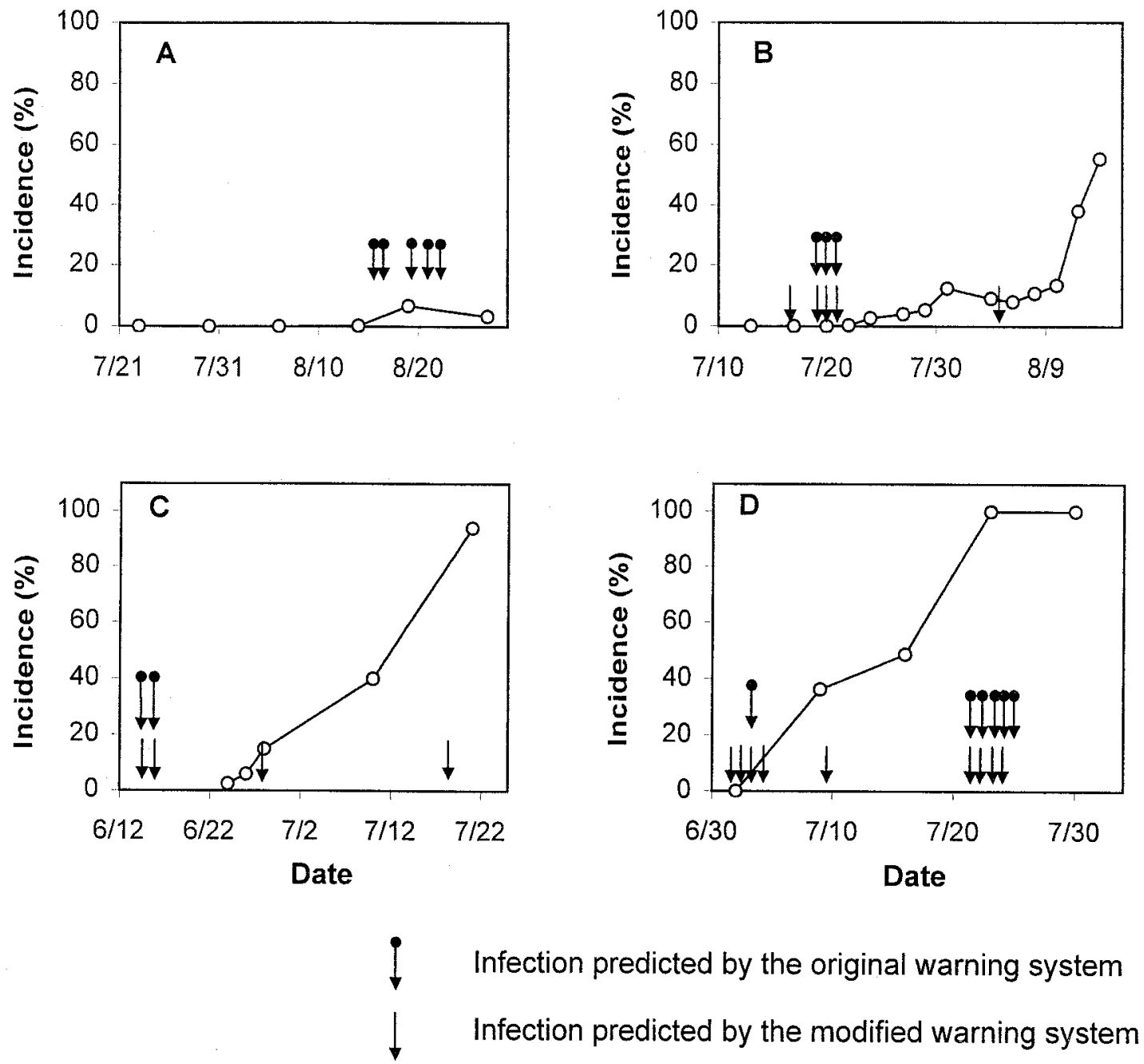

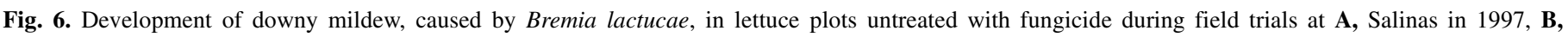

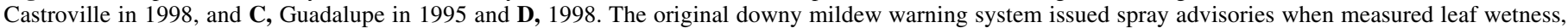

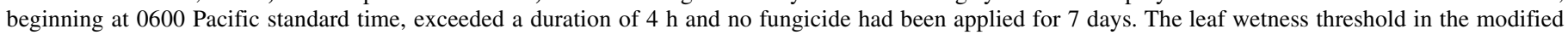

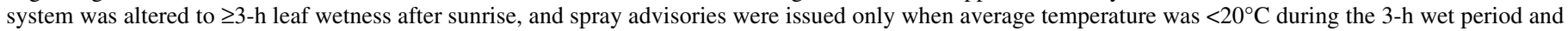
$<22^{\circ} \mathrm{C}$ during the subsequent 4 -h period. 
TABLE 1. Number of fungicide applications recommended by the original and modified warning systems for downy mildew of lettuce during 14 field studies in coastal California between 1993 and $1998^{a}$

\begin{tabular}{|c|c|c|c|c|}
\hline \multirow[b]{2}{*}{$\begin{array}{l}\text { Disease } \\
\text { potential }^{\text {b }}\end{array}$} & \multirow[b]{2}{*}{ Study site and season } & \multirow{2}{*}{$\begin{array}{c}\text { Disease } \\
\text { incidence at } \\
\text { harvest }(\%)\end{array}$} & \multicolumn{2}{|c|}{$\begin{array}{c}\text { Number of sprays } \\
\text { recommended }\end{array}$} \\
\hline & & & $\begin{array}{l}\text { Modified } \\
\text { system }\end{array}$ & $\begin{array}{c}\text { Original } \\
\text { system }\end{array}$ \\
\hline \multirow[t]{7}{*}{ Low } & Salinas (summer 1993) & 0.0 & 0 & 0 \\
\hline & Salinas (summer 1993) & 0.0 & 0 & 0 \\
\hline & Soledad (summer 1996) & 0.3 & 0 & 0 \\
\hline & Salinas (fall 1995) & 1.0 & 2 & 2 \\
\hline & Salinas (summer 1997) & 4.0 & 0 & 1 \\
\hline & Salinas (summer 1994) & 20.0 & 1 & 2 \\
\hline & & 4.2 & 0.50 & 0.83 \\
\hline \multirow[t]{9}{*}{ High } & Castroville (summer 1998) & 55.3 & 2 & 1 \\
\hline & Guadalupe (summer 1995) & 94.0 & 3 & 1 \\
\hline & Castroville (fall 1995) & 99.0 & 3 & 3 \\
\hline & Guadalupe (summer 1994) & 100.0 & 3 & 3 \\
\hline & Castroville (summer 1995) & 100.0 & 2 & 2 \\
\hline & Guadalupe (spring 1995) & 100.0 & 3 & 2 \\
\hline & Salinas (summer 1995) & 100.0 & 3 & 2 \\
\hline & Guadalupe (summer 1998) & 100.0 & 3 & 2 \\
\hline & & 93.5 & 2.75 & 2.00 \\
\hline
\end{tabular}

a The original system issued spray advisories when measured morning leaf wetness, beginning at 0600 Pacific standard time, exceeded a duration of $4 \mathrm{~h}$ and no fungicide had been applied for 7 days. The leaf wetness threshold in the modified system was altered to $\geq 3$-h leaf wetness after sunrise, and spray advisories were issued only when average temperature was $<20^{\circ} \mathrm{C}$ during the 3 -h wet period and $<22^{\circ} \mathrm{C}$ during the subsequent 4 -h period.

${ }^{\mathrm{b}}$ Fields were classified as having been exposed to low or high disease potential based on whether final disease incidence, assessed on at least three sets of 50 to 100 untreated plants, was below or above $50 \%$.

did not become apparent until this study was completed. Nevertheless, the results presented here make it evident that the modifications can improve the original system considerably. Further field tests to validate and implement the modified system are now needed.

\section{ACKNOWLEDGMENTS}

This research was supported by the California Lettuce Advisory Board, Smith-Lever IPM grants (96SL019 and 97SL001) to K. V. Subbarao and A. H. C. van Bruggen, and a USDA-NRI grant (96-353133752) to A. H. C. van Bruggen, K. V. Subbarao, and R. W. Michelmore. We thank all those who offered us cooperation during the past 8 years.

\section{LITERATURE CITED}

1. Crute, I. R., and Dixon, G. R. 1981. Downy mildew diseases caused by the genus Bremia Regel. Pages 421-459 in: The Downy Mildews. D. M. Spencer, ed. Academic Press, New York.
2. Fletcher, J. 1976. Bremia lactucae oospores, sporangial dissemination and control. Ann. Appl. Biol. 84:294-298.

3. Hyre, R. A. 1964. High temperature following infection checks downy mildew of lima bean. Phytopathology 54:181-184.

4. Michelmore, R. W., and Ochoa, O. E. 1997. Lettuce Breeding. Pages 3443 in: Annu. Rep. Calif. Iceberg Lettuce Res. Board, Salinas, CA.

5. Populer, C. 1981. Epidemiology of downy mildews. Pages 57-105 in: The Downy Mildews. D. M. Spencer, ed. Academic Press, New York.

6. Powlesland, R. 1954. On the biology of Bremia lactucae. Trans. Br. Mycol. Soc. 37:362-371.

7. Sargent, J. A., Tommerup, L. C., and Ingram, D. S. 1973. The penetration of a susceptible lettuce variety by the downy mildew fungus Bremia lactucae Regel. Physiol. Plant Pathol. 3:231-239.

8. Scherm, H., Koike, S. T., Laemmlen, F. F., and van Bruggen, A. H. C. 1995. Field evaluation of fungicide spray advisories against lettuce downy mildew (Bremia lactucae) based on measured or forecast morning leaf wetness. Plant Dis. 79:511-516.

9. Scherm, H., and van Bruggen, A. H. C. 1993. Response surface models for germination and infection of Bremia-lactucae, the fungus causing downy mildew of lettuce. Ecol. Model. 65:281-296.

10. Scherm, H., and van Bruggen, A. H. C. 1993. Sensitivity of simulated dew duration to meteorological variations in different climatic regions of California. Agric. For. Meteorol. 66:229-245.

11. Scherm, H., and van Bruggen, A. H. C. 1994. Effects of fluctuating temperatures on the latent period of lettuce downy mildew (Bremia lactucae). Phytopathology 84:853-859.

12. Scherm, H., and van Bruggen, A. H. C. 1994. Weather variables associated with infection of lettuce by downy mildew (Bremia lactucae) in coastal California. Phytopathology 84:860-865.

13. Scherm, H., and van Bruggen, A. H. C. 1995. Concurrent spore release and infection of lettuce by Bremia lactucae during mornings with prolonged leaf wetness. Phytopathology 85:552-555.

14. Schettini, T. M., Legg, E. J., and Michelmore, R. W. 1991. Insensitivity to metalaxyl in California populations of Bremia lactucae and resistance of California lettuce cultivars to downy mildew. Phytopathology 81:64-70.

15. Schnathorst, W. C. 1962. Comparative ecology of downy and powdery mildews of lettuce. Phytopathology 52:41-46.

16. Su, H., van Bruggen, A. H. C., and Subbarao, K. V. 1998. Moving air and relative humidity affect sporulation of Bremia lactucae. (Abstr.) Phytopathology 88(suppl.):S86.

17. Su, H., van Bruggen, A. H. C., and Subbarao, K. V. 2000. Spore release of Bremia lactucae on lettuce is affected by timing of light initiation and decrease in relative humidity. Phytopathology 90:67-71.

18. Verhoeff, K. 1960. On the parasitism of Bremia lactucae Regel on lettuce. Tijdschr. Plantenziekten. Ziekten 66:133-203.

19. Wallin, J. R. 1953. The production and survival of sporangia of Phytophthora infestans on tomato and potato plants in the field. Phytopathology 43:505-508.

20. Wu, B. M., Subbarao, K. V., and van Bruggen, A. H. C. 1998. Effects of solar radiation on survival of Bremia lactucae sporangia on lettuce leaves. (Abstr.) Phytopathology 88(suppl.):S99.

21. Wu, B. M., Subbarao, K. V., and van Bruggen, A. H. C. 2000. Factors affecting the survival of Bremia lactucae sporangia deposited on lettuce leaves. Phytopathology 90:827-833.

22. Wu, B. M., Subbarao, K. V., van Bruggen, A. H. C., and Koike, S. T. 2001. Comparison of three fungicide spray advisories for lettuce downy mildew. Plant Dis. 85:895-900.

23. Yuen, J., Twengström, E., and Sigvald, R. 1996. Calibration and verification of risk algorithms using logistic regression. Eur. J. Plant Pathol. 102:847-854. 